\title{
Challenges and Opportunities in Marx's Education under Network Environment
}

\author{
LiuWeiyang \\ Nanchang Institute of Science \&Technology,Nanchang 330108,China
}

\begin{abstract}
Keywords: Marxism education; Network; Challenge and opportunity; Methods and assessment; TOPSIS
\end{abstract}

\begin{abstract}
Network teaching is virtual technology to realize the information exchange platform, Marxism needs the value of its platform to be effective, it can also use the internet information platform to enhance Marxism teaching's effectiveness and significance, so as to improve the teaching itself initiative value. Network thought political education is conducive to the realization of the Marxism education method innovation, more conducive to the development of a broad range of Marxism education, Marxism workers should hit out actively, at the same time to give full play to network anonymous communication, communication freedom real and other advantage, the implementation of educator's communicate effectively can enhance the pertinence and timeliness of Marxism education.
\end{abstract}

\section{Introduction}

Internet refers to two computers or two or more computer terminals, client and service that are connected with the results by means of computer information technology means, which has wide propaganda and mass storage capacity of virtual space. On the internet platform, information exchange work has the effectiveness, timeliness, openness, extensiveness, interaction, virtual sex and other characteristics, these characteristics are the main force of the internet as a new industrial development, at the same time to provide a guarantee on the internet teaching [1]. Marxism education as an effective education way of establishing teenagers' healthy personality and correct learning attitude has put forward higher requirements on adolescents' mental health and personality health, and occupies an important position in the teenagers' physical and mental quality development. Along with the accelerating ceaselessly of our country economy development speed, economic development scale has been gradually expanded, so the internet will become a necessary means of education and teaching [2]. Through the network information teaching, it will be a large number of information sharing, using video and remote dynamic teaching can help political thought to better improve the quality of students, then through the teaching methods of network Marxism education diversification, strengthening the Marxism guidance value, to improve the deficiencies and shortcomings of Marxism education. For college students' Marxism education, network Marxism education is the kind of teaching means and methods of communication and platform sharing, but also students learn the major media and platforms of Marxism, so Marxism education also must meet the requirements of the times and the characteristics, combining elements of development to improve the development power of Marxism education, changing the traditional teaching ideas and viewpoints of thought political to improve the targeted of the work object and strengthen the competence of work [3-4].

\section{Marxism education opportunities under the internet environment}

Opportunity analysis of Marxism education under the internet environment. The internet is modern society new information dissemination and teaching communication's development approaches and tools, internet teaching is a way of sustainable development and the platform, the internet helps Marxism work find innovative teaching node. Network platform is not the limit of time and space [5], and the internet platform is an interactive network platform, which has sustainable driving force for network information development, the Marxism education tends to be 
large-scale and standardization in the promotion of network platform. According to the twenty-ninth China internet development survey of China internet network information center (CNNIC), the main groups of Chinese current network users are 10-39 years old adolescents, young and middle-aged; this kind of person is the main force of Chinese internet users. In 2015, 10-19 years old Chinese network users are the proportion of $26.7 \%$ in the whole internet users, $20-29$ years old Chinese network users are the proportion of 29.8\%, and 30-39 year old Chinese network users are proportion of $25.7 \%$ in the overall internet users; its specific situation is shown in Fig.2 [6].

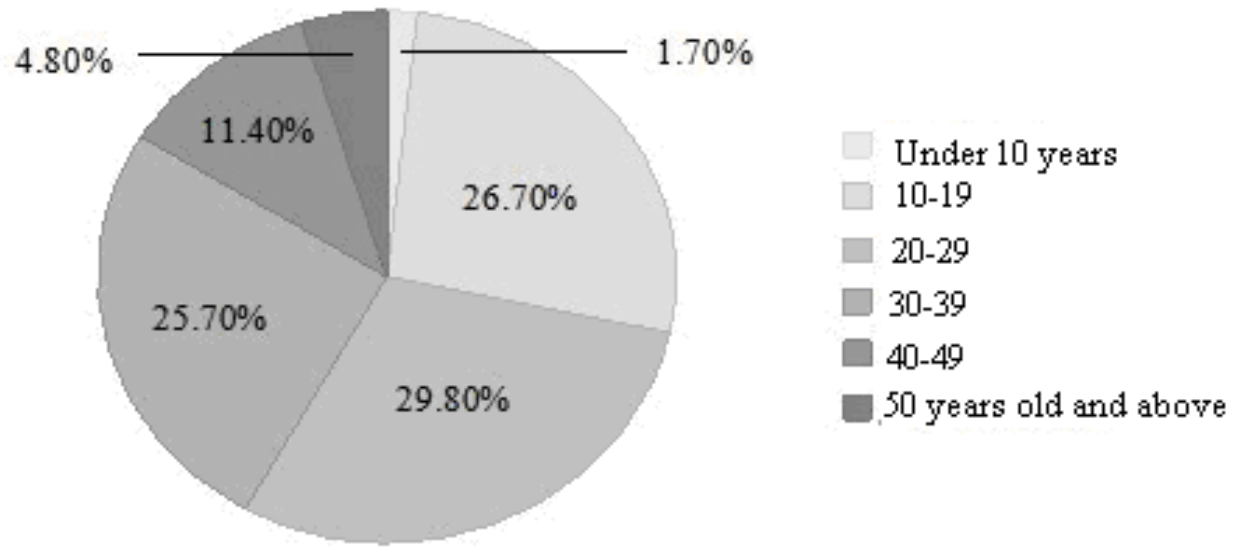

Fig.1 Chinese netizen integral age structure comparison in 2015

As shows Figure 1, the number of Chinese netizen adolescents is accounted for $82.2 \%$ in the overall internet users, which can be said that Marxism education has a considerable challenge under the internet environment. Network information technology has not only changed the way of acquisition, transfer and release information, but also changes the communication way between educators and students. The network has changed the traditional ideas and old teaching model, to improve teaching effectiveness and teaching innovation[7]. However the traditional teaching methods did not distinguish education initiative in education link, the leader of traditional teaching did not arouse learners' interest and spontaneous learning motivation, which will reduce the students learning Marxism curriculum initiative, the use of network teaching can improve the Marxism education information communication function and ideological dynamic ideology exchanges, through the dynamic information exchanges and communication constantly improve the Marxism course teaching significance.

Advantage analysis of Marxism education under the internet environment. The network contains a lot of information technology theory and problems, which will not only shorten the distance between teachers and students, but also shorten the advanced theory information for real-time updates and off-line learning classroom teaching interaction distance, it can make the teacher more convenient control network latest theory of technology advantages, which can carry out theory knowledge to explain in the classroom, improving students learning Marxism theory knowledge power, and improving the traditional Marxism education's way and content, in the Marxism education to establish a good communication, the establishment of a new teaching image can provide new objects and new course reference for the Marxism work [8]. Through the network of Marxism education, it can make more students understand the Marxism theory teaching content, to master students most need of Marxism interest topic and learning trends. Marxism education advantages under the internet environment are shown in Figure 2. 


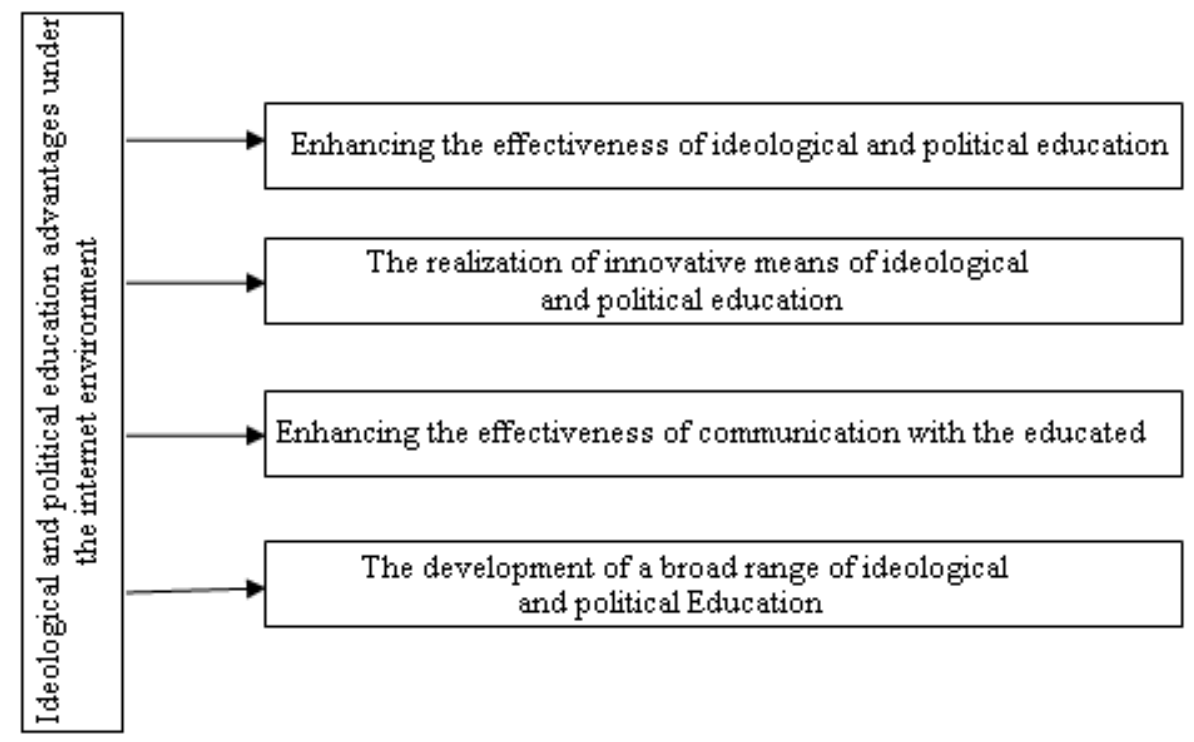

Fig. 2. Marxism education advantages under the internet environment

As shown in Figure 2, the Marxism education under the internet environment is conducive to enhance the effectiveness of Marxism education effect, the internet link effect manifests its power source in interactive teaching mode, which can help students improve their automatic spontaneous of learning knowledge, making the student can fully get the exchange when they accept the education; Being advantageous to the enhancement the effectiveness with the educated communication, compared with traditional education, using the internet to develop the Marxism education is more flexible, diverse ways, communication freedom and other characteristics; through the interactive and open teaching development, enhancing ego to the Marxism theory knowledge's understanding ability, and also corresponding to master a variety of effective Marxism theoretical resources and information, to make more many students understand through the ideological and politician's latest theory [9], school scholarly account, social practice information and so on, so as to master the Marxism education of the real internet platform model, understanding the importance of Marxism education.

\section{Challenge of Marxism education under the internet environment}

The internet open nature leads to western culture and values permeability increasing. In the global information infrastructure of America information superhighway plan, it has referred that the rapid development of the global infrastructure will promote the principles of democracy, limiting the spread of totalitarian forms: through the global infrastructure, the citizens of the world will have the opportunity to access to the same information and the same standards, so that the world has a greater sense of commonality [10]. Thus, the United States develops the purpose of the "information freeway " purpose, which is not only limited to the development of economy and technology, it is to make full use of its information transmission control and influence, so as to dominate the world with the western ideology, political system, culture and values, to make it become the world's common guidelines. In China internet users' academic structure, it can be found that the populations of most internet users are high school education, this crowd is the highest on the utilization rate of social networking website, reaching 61.8\%. Another high school level educated and college-educated people on the use of social networking sites are more than 50\%, Chinese netizen degree structure specific distribution as shown in Figure 3. 


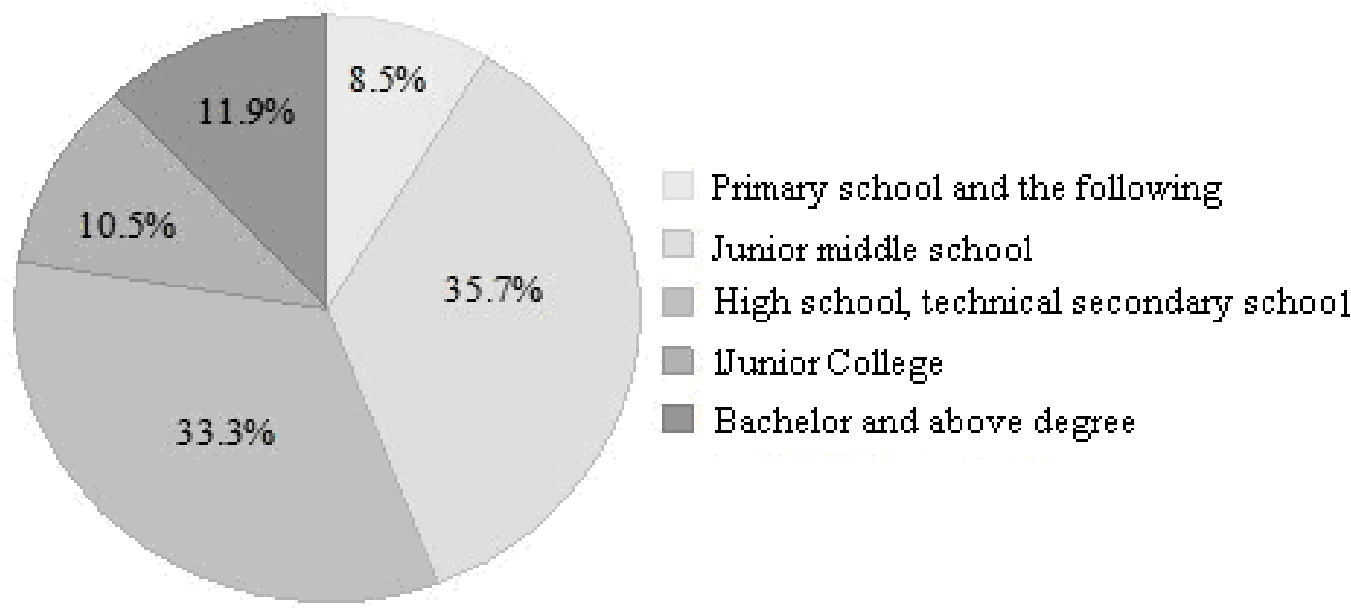

Fig. 3 Chinese netizens integral degree structure comparison in 2015

Marxism education in the network is still almost an uncultivated virgin land, even if the individual website has started to try this respect, which also like a leaf Guzhou in the vast network ocean, making the Marxism education effectiveness is relatively abate. The role of traditional Marxism education's subject-object is obvious, however on the internet, for an object with replace effect, i.e. in a certain period of time and space, the object receiving, processing various information quantity is limited, when some information increases, the corresponding additional information will be reduced. Under the internet environment, the inferior of Marxism education is mainly three aspects as shown in Figure 4.

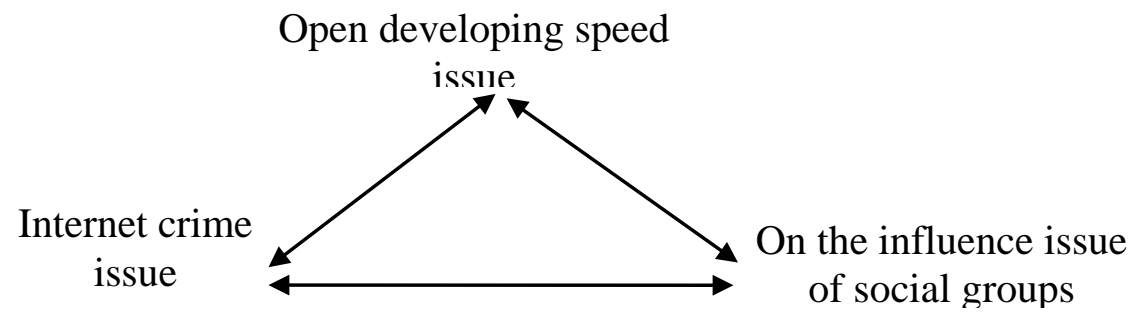

Fig. 4. The main disadvantage of the Marxism education under the internet circumstance

\section{Optimization of network Marxism education measures and evaluation}

How to use internet to develop the Marxism education, the need to change the traditional Marxism teaching views, vigorously developing the Marxism network teaching, eliminating social practical obstacle, and ensuring public Marxism welfare and benefits, the school need to set up their own Marxism education curriculum, it can establish student of the new goal learning Marxism with correct, positive, effective, healthy Marxism education culture to improve content, which can make students learning more interesting, maintaining full enthusiasm. In the process of network Marxism education teaching, people should pay attention to the ways of exploring and decision analysis, network Marxism education approaches are mainly four aspects, specifically as shown in table 1.

Tab. 1 The network Marxism education measures

\begin{tabular}{|c|c|}
\hline Aspect & Measures \\
\hline First aspect & $\begin{array}{c}\text { Innovation thought, promoting dominant thought, } \\
\text { occupying network position }\end{array}$ \\
\hline Second aspect & $\begin{array}{c}\text { Using internet, providing service, building new } \\
\text { education relationship }\end{array}$ \\
\hline Third aspect & $\begin{array}{c}\text { Perfect regulations, conducting propaganda } \\
\text { network civilization, strengthening self-discipline } \\
\text { education; }\end{array}$ \\
\hline Fourth aspect & $\begin{array}{c}\text { Social support, providing material guarantee, } \\
\text { encouraging exploration innovation }\end{array}$ \\
\hline
\end{tabular}


In the optimization of network Marxism education measures assessing, using TOPSIS scheme evaluation to the decision-making network Marxism education, its basic concept is gap between the best scheme and the worst scheme to measure network Marxism education, at the same time to carry out decision-making optimization, its sketch map is shown in Figure 5.

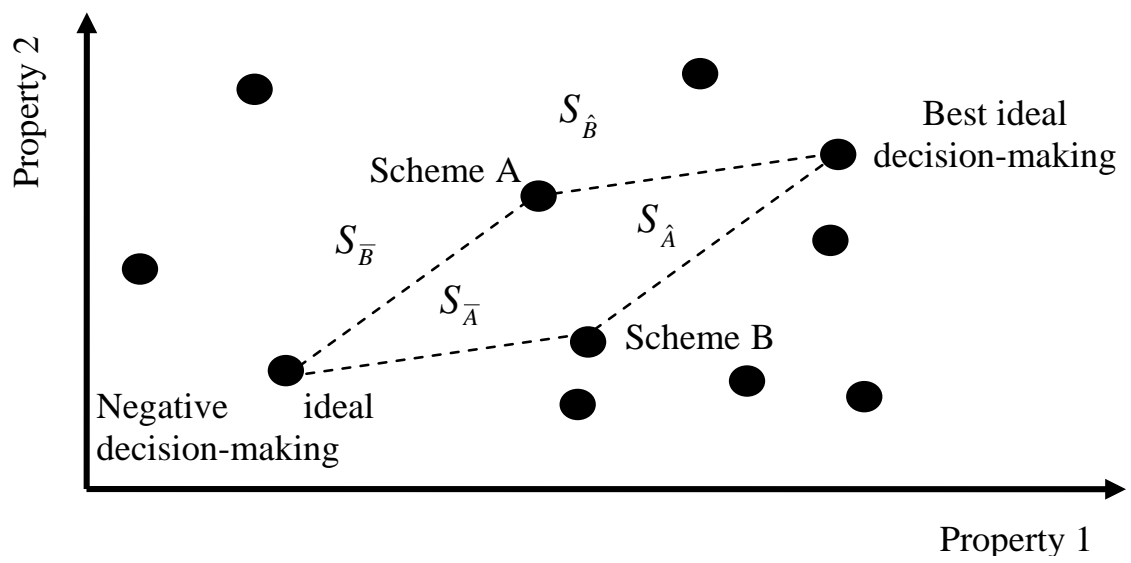

Fig. 5 The network Marxism education measures assessing optimization scheme sketch map

As shown in Figure 5, the distance between optimization scheme and the best decision is $S_{\hat{B}}$ in network Marxism education measures assessing optimization based on TOPSIS, and the distance between the negative ideal decision-making is $S_{j}$. Between $\mathrm{A}$ and $\mathrm{B}$, the scheme respectively uses $S_{\hat{A}}, S_{\bar{A}}, S_{\hat{B}}$ and $S_{\bar{B}}$ to represent, which are connected by dashed lines. The closer from the ideal distance, then network Marxism education under the measure is better. In view of the different decision-making, using the weight coefficient's weighted model can obtain the program optimization effect, as shown in the following formula:

$$
V\left(S_{j}\right)=\omega_{1} V\left(x_{1}\right)+\omega_{2} V\left(x_{2}\right)+\ldots+\omega_{n} V\left(x_{n}\right)
$$

In network era, the Marxism education has been put forward higher requirements, people should do a good job of Marxism education to enter the network. The first must have a good political quality, ideological and moral correct, awareness of science and technology and innovation ability, high level of business's Marxism education team. People can always use the Marx doctrine occupation school ideological and cultural position, so as to effectively prevent network wrong ideas and the dissemination of information. People need to take corresponding measures and needs a scientific network Marxism education measures assessing optimization, using cyber source collection platform and information to grasp and understand more about the people-oriented and scientific development thought's Marxism knowledge and theories, to make the internet better for the Marxism education serve.

\section{Conclusion}

The development of internet has put forward higher requirements and conditions on college students' Marxism education teaching, and has opened up a new channel on the development of network platform Marxism education innovation to raise new requirement. In view of the current network Marxism education situation cognitive analysis, to scientific analyze the opportunities and challenges of Marxism education under the environment of internet based on the investigation, and to further deepen research, using the internet to carry out network Marxism education's evaluation methods. Through the new era of network Marxism education teaching methods, strengthening the Marxism education should meet the development requirements of the times, to improve the traditional Marxism education teaching means. 


\section{References}

[1] LiHaixin. Research on college students' Marxism education under network environment [D]. Hebei normal university, 2010(9): 45-68.

[2] SongDi. Internet age Marxism education [J]. Lanzhou institute of education, 2009(1): 3-6.

[3] DongYaping Opportunities, challenges and ways of Marxism education networking [J]. Marxism education research, 2010(10): 44-47.

[4] WangYinSheng. Present situation and analysis of university network Marxism work [J]. Jianghuai forum, 2005 (1): 145-146.

[5] GeChenGuang. Approach exploration of Marxism education in the network [J]. Education exploration, 2009 (11): 121-122.

[6] ZhangQianWen, ZhouPingting, MaXiaoQian. Exploration of the university network Marxism work [J]. Chinese geological education, 2005(3): 132-133.

[7] DengLiMin. Characteristic and channel of the network Marxism work [J]. Journal of South-Central university for nationalities (Humanities and social sciences edition), 2010 (5): 142-143.

[8] JiaHuaiqin. Data, model and decision [D]. International economics business university press, 2004: 89-110.

[9] RongShanShan. Research on Anhui college students' network literacy and its education practice [D]. Wuhu: Anhwei normal university, 2007(12): 2-15.

[10] Application of China online social networking site report research in 2015 [M]. China internet network information center, 2012(3): 123-133. 